\title{
Design and Development of Automatic Water Level and Quality Warning System of Latphrao Canal Community Bangkok, Thailand
}

\author{
Keeradit Saiapattalung, Thongchai Thongyoo, Hattaya Netayaraks, Lakkana Ruekkasaem, \\ Pasura Aungkulanon
}

\begin{abstract}
The objectives of this research were to design and develop an automatic water level warning system for communities living along Khlong Lad Phrao (Lad Phrao Canal) in Bangkok. The development of the system was divided into the following four main parts: 1) a water level measurement system; 2) a precipitation measurement system; 3) a water quality testing system covering dissolved oxygen, $\mathrm{pH}$, turbidity and electrical conductivity and 4) an internet alert system utilizing the LINE application and web-based application information display. The first three parts were to be solar-powered. The design and development effort showed that the system successfully measured water levels along with water quality with speed and precision. Moreover, the system was easy to measure results and was able to alert through the LINE application when water in Khlong Lad Phrao approached critical levels, thereby reducing damage from water levels. Precision testing of the developed water level and quality measurement systems found that precision was in the range of $99.74-99.77 \%$.
\end{abstract}

Keywords: Water quality, Water level measurement equipment, and Internet alert system.

\section{INTRODUCTION}

Khlong Lad Phrao is 24.5 kilometers long, so it is one of the longest canals in Bangkok, Thailand. Khlong Lad Phrao flows through many districts of Bangkok, namely, Sai Mai, Lak Si, Don Mueang, Bang Khen, Chatuchak, Huai Khwang and Wang Thong Lang districts, all combining to 52 communities, 7,314 households, 10,971 families, and 43,116 people. As a result, many problems such as floods can occur, especially due to house encroachment of canal areas, which

Revised Manuscript Received on February 15, 2020.

* Correspondence Author

Keeradit Saipattalung*, Department of Electronics and Computer Technology. Faculty of Industrial Technology Phranakhon Rajabhat University, Bangkok, Thailand. Email: keeradit@pnru.ac.th

Thongchai Thongyoo, Department of Electronics and Computer Technology. Faculty of Industrial Technology Phranakhon Rajabhat University, Bangkok, Thailand. Email: thongcht@pnru.ac.th

Hattaya Netayaraks, Department of Environmental Science and Technology. Faculty of Science and Technology Phranakhon Rajabhat University, Bangkok, Thailand. Email: hattayanet@hotmail.com

Lakkana Ruekkasaem, Faculty of Industrial Technology, Phranakorn Rajabhat University, Bangkok, Thailand Email: lakkana@pnru.ac.th

Pasura Aungkulanon, Department of Materials Handling and Logistics Engineering, Faculty of Engineering, King Mongkut's University of Technology North Bangkok, Bangkok, Thailand Email: pasura.a@eng.kmutnb.ac.th

(C) The Authors. Published by Blue Eyes Intelligence Engineering and Sciences Publication (BEIESP). This is an open access article under the CC BY-NC-ND license (http://creativecommons.org/licenses/by-nc-nd/4.0/) lead to water flow problems, community wastes, environmental impacts and water quality problems. [1-6]

Community based survey of problems and contexts of the sampled areas found that most houses located alongside the canal and these houses are constructed next to each other, thereby causing many community problems. The common problem was flooding due to heavy rains and scheduling of water gates. In addition, water quality statistics for Khlong Lad Phrao indicated very poor water quality. By this, the average amount of dissolved oxygen in the water was less than 1 milligram per liter, and every random test site was inhospitable to life (Department of Drainage and Sewerage, Bangkok, 2012). [7,8] As the aforementioned value is a critical value, Khlong Lad Phrao requires urgent management, especially in terms of its water quality, in order to maintain good quality of living in the people who live alongside Khlong Lad Phrao. Thus, the automatic water level and quality alert system were proposed in to tackle these problems. The system was developed into the following four separate parts: 1) a water level measurement system; 2) a precipitation measurement system; 3) a water quality testing system covering dissolved oxygen, $\mathrm{pH}$, turbidity, and electrical conductivity values and 4) a real-time alert system utilizing the LINE application and web-based application information display. The first three parts uses solar power, and this system would be able to create a safety standard for communities as well as raise community quality of life and environmental quality.

\section{METHOD}

The tool was developed using sensor and programming system for testing of the quality of water in real-time. The conceptual framework consists of 4 processes including measurement system design, electronic circuits and programing system, sensor detection, and valve testing.

\section{1) Measurement system design.}

Step 1 consisted of designing the measurement process for each type of sensor. All seven monitoring stations, used Arduino Mega microcontrollers for central processing units, were divided into two parts, which were stations consisted of water level monitoring and water quality monitoring stations. $[9,10]$ The system is updated using the Internet and solar powered. Water level alerts could be issued through the LINE application, and results can be displayed on a web-based application (Node Red) in graph and numeral forms as provided by all seven monitoring stations. 
Therefore, communities were able to learn about water levels and quality in a timely manner, as shown in Fig. 1(a) and 1(b).

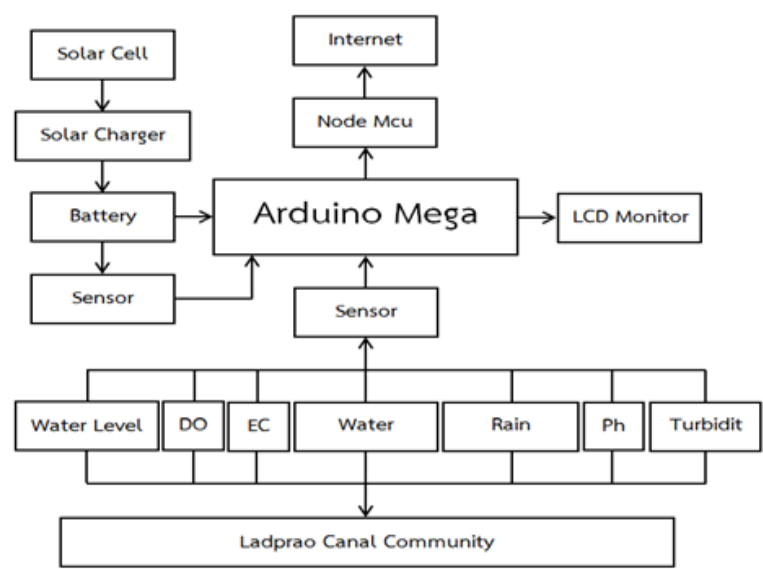

(a)

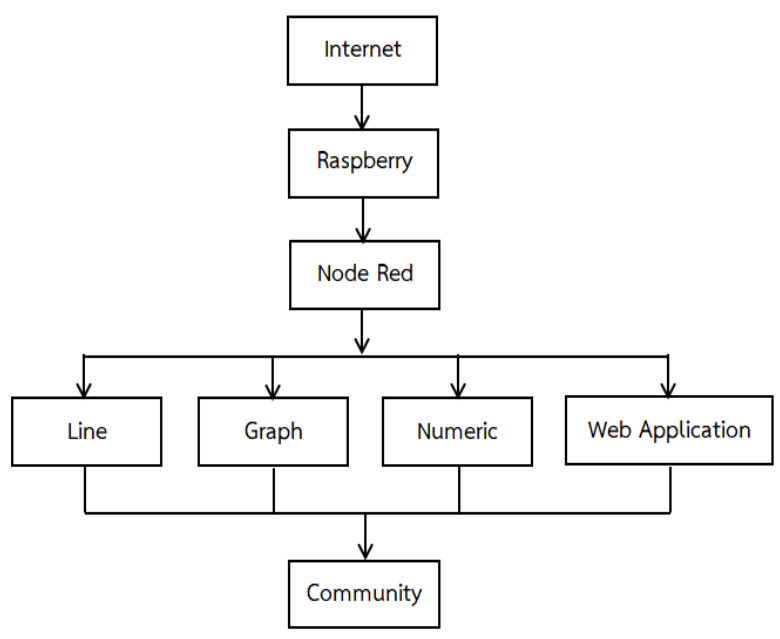

(b)

\section{2) Electronic circuits and systems program}

Step 2 consisted of designing the electronic circuits for all seven monitoring stations. Microcontrollers, sensors and Internet of Things (IoT) were all connected. Monitoring parameters consisted of the following: 1) water levels; 2) precipitation; and 3) water quality, as shown in Fig. 2.

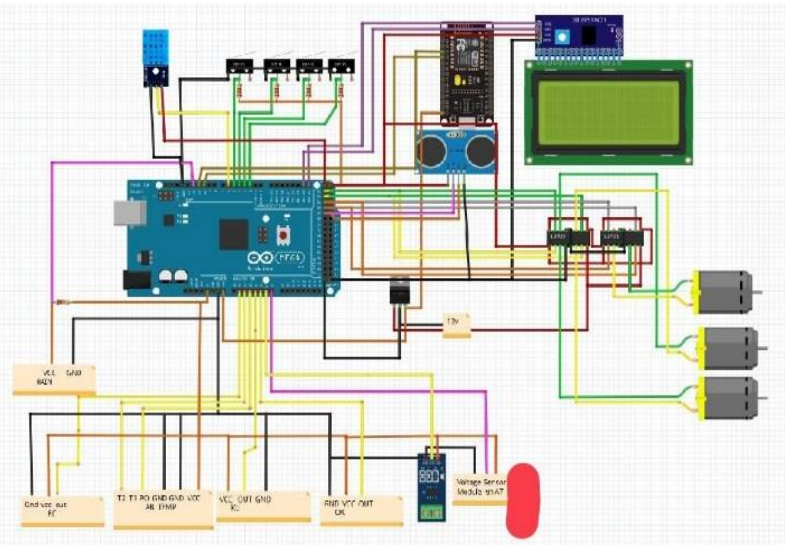

Fig 2. Drawing of electronic circuit

\section{3) Sensor detection}

Step 3 consisted of the designing of the drive system.
Monitoring sensors consisted of the following two sets: 1) ranging modules and 2) water quality sensors. The drive system was designed to achieve upward and downward motion by a servomotor installed with 3D-printed plastic from PLA plastic pieces capable of being constructed independently, as shown in Fig. 3.
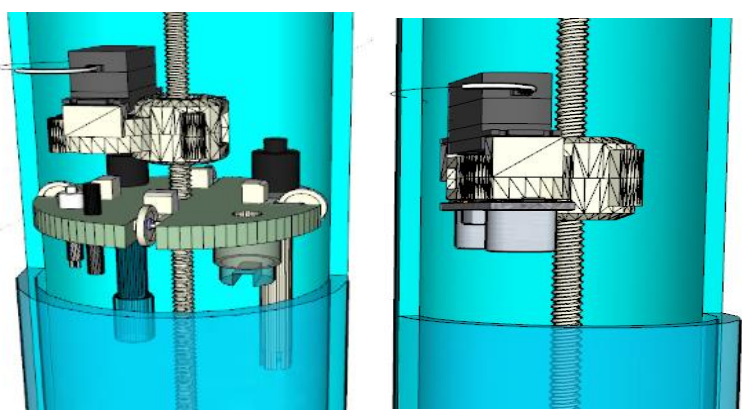

Fig 3. Installation sensor

\section{4) Valve testing}

Step 4 consisted of testing measurement values produced by the designed sensors in comparison with standard measurement instruments. In Step 3 of design, the sensor readings were mostly analog, so it was necessary to construct equations to convert analog values to desired measurement units. This was achieved by comparing measured values with the standard water quality measurement instrument Hanna Instruments HI9829 from Romania (Hanna Instruments, 2015). Comparative water quality measurements of all seven water sources at Phranakhon Rajabhat University, Bangkok, Thailand, were taken as shown in Fig. 4(a) and 4(b) along with $\mathrm{pH}$ measurements between the standard instrument in Table 1 and the developed sensor system shown in Table 2 from seven water sources

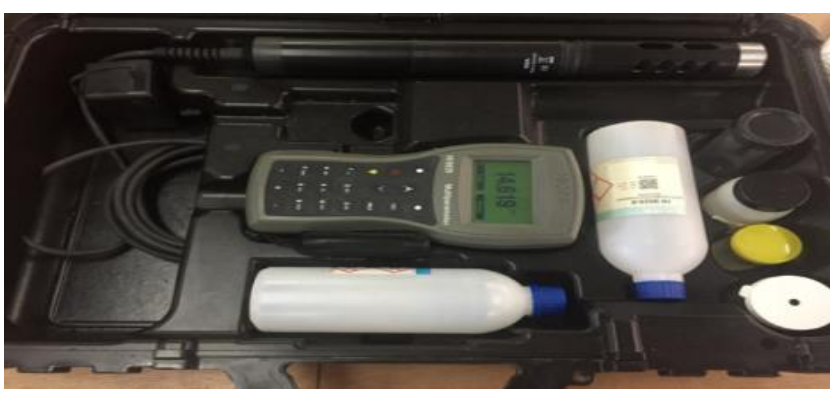

(a)

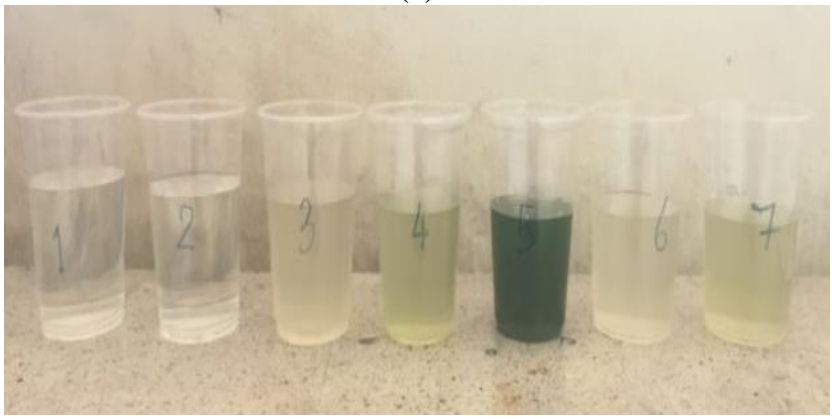

(b)

Fig. 4 Water testing 7 samples 
Table- I: Results pH from standard equipment

\begin{tabular}{|c|c|c|c|c|c|c|c|}
\hline $\begin{array}{c}\text { Record } \\
\text { no. }\end{array}$ & 1 & 2 & 3 & 4 & 5 & 6 & 7 \\
\hline 1 & 6.31 & 6.24 & 6.23 & 6.23 & 6.23 & 6.21 & 6.23 \\
\hline 2 & 6.31 & 6.25 & 6.23 & 6.20 & 6.25 & 6.22 & 6.24 \\
\hline 3 & 6.29 & 6.25 & 6.22 & 6.24 & 6.24 & 6.23 & 6.23 \\
\hline 4 & 6.33 & 6.23 & 6.21 & 6.23 & 6.23 & 6.19 & 6.24 \\
\hline 5 & 6.31 & 6.24 & 6.22 & 6.23 & 6.23 & 6.23 & 6.22 \\
\hline
\end{tabular}

Table- II: Results of pH from new testing equipment

\begin{tabular}{|c|c|c|c|c|c|c|c|}
\hline $\begin{array}{c}\text { Record } \\
\text { no. }\end{array}$ & 1 & 2 & 3 & 4 & 5 & 6 & 7 \\
\hline 1 & 6.31 & 6.22 & 6.23 & 6.23 & 6.23 & 6.21 & 6.22 \\
\hline 2 & 6.32 & 6.24 & 6.22 & 6.24 & 6.24 & 6.22 & 6.24 \\
\hline 3 & 6.31 & 6.22 & 6.24 & 6.25 & 6.25 & 6.24 & 6.24 \\
\hline 4 & 6.33 & 6.24 & 6.23 & 6.24 & 6.23 & 6.23 & 6.22 \\
\hline 5 & 6.30 & 6.21 & 6.22 & 6.24 & 6.24 & 6.22 & 6.23 \\
\hline
\end{tabular}

According to Tables I and II, the $\mathrm{pH}$ values measured from the developed sensor set were converted by a mathematical formula to produce values in the desired units as follows:

$$
\mathrm{pH}=8+\frac{2.5-\text { vltValue }}{0.18}
$$

Where (1) represents the mathematic function for calculate the potential of hydrogen ion or $\mathrm{pH}$. The vltValue equals measuringVal * (5/1024) and measuringVal is the value from sensor no.3 of Arduino Mega.

The amount of dissolved oxygen in the seven water sources at Phranakhon Rajabhat University was measured using the standard measurement instrument as shown in Table III and the developed sensor set as shown in Table IV.

$$
D O=5+\frac{2.5-\text { vltValue } 1}{0.18}
$$

Where (2) represents the value of dissolved oxygen or DO. The vltValue is calculated from measuringVal * $(5 / 1024)$.

Table- III: Results of dissolved oxygen from standard equipment

\begin{tabular}{|c|c|c|c|c|c|c|c|}
\hline $\begin{array}{c}\text { Record } \\
\text { no. }\end{array}$ & 1 & 2 & 3 & 4 & 5 & 6 & 7 \\
\hline 1 & 5.04 & 5.50 & 4.24 & 4.57 & 2.91 & 4.35 & 4.40 \\
\hline 2 & 5.05 & 5.51 & 4.25 & 4.56 & 2.92 & 4.36 & 4.38 \\
\hline 3 & 5.06 & 5.49 & 4.26 & 4.55 & 2.92 & 4.35 & 4.39 \\
\hline 4 & 5.04 & 5.49 & 4.25 & 4.56 & 2.91 & 4.34 & 4.39 \\
\hline 5 & 5.03 & 5.51 & 4.25 & 4.56 & 2.93 & 4.36 & 4.38 \\
\hline
\end{tabular}

Table- IV: Results of dissolved oxygen from new testing equipment

\begin{tabular}{|c|c|c|c|c|c|c|c|}
\hline $\begin{array}{c}\text { Record } \\
\text { no. }\end{array}$ & 1 & 2 & 3 & 4 & 5 & 6 & 7 \\
\hline 1 & 5.04 & 5.50 & 4.24 & 4.57 & 2.91 & 4.35 & 4.40 \\
\hline 2 & 5.05 & 5.51 & 4.25 & 4.56 & 2.92 & 4.36 & 4.38 \\
\hline 3 & 5.06 & 5.49 & 4.26 & 4.55 & 2.92 & 4.35 & 4.39 \\
\hline 4 & 5.04 & 5.49 & 4.25 & 4.56 & 2.91 & 4.34 & 4.39 \\
\hline 5 & 5.03 & 5.51 & 4.25 & 4.56 & 2.93 & 4.36 & 4.38 \\
\hline
\end{tabular}

\section{RESULTS}

In the design of the system's structure, the electronic circuitry was designed for central processing in each station with connections for microcontrollers, sensors, Internet of Things, the drive system, water level monitoring and water quality monitoring sensors. The monitoring procedures for the values of each sensor and display formats are the same for all seven stations as shown in Fig. 5.

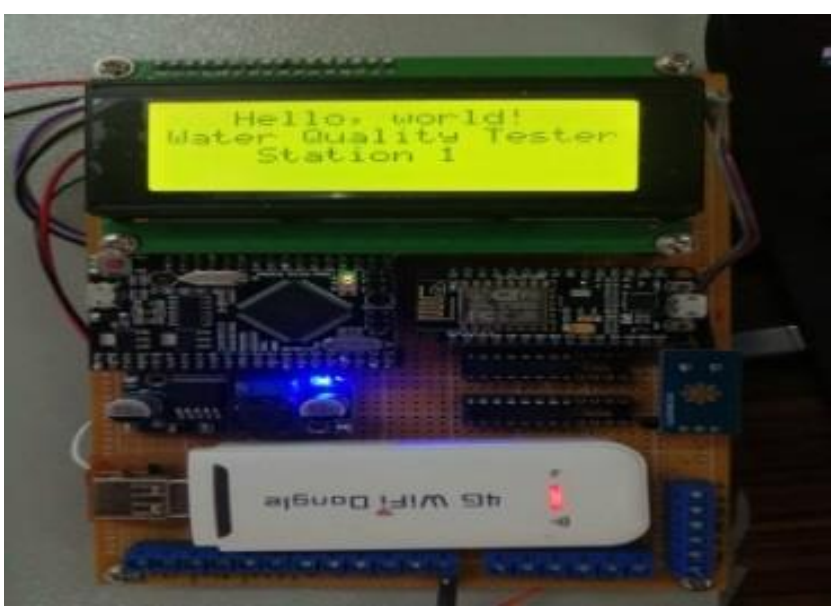

(a)



(b)

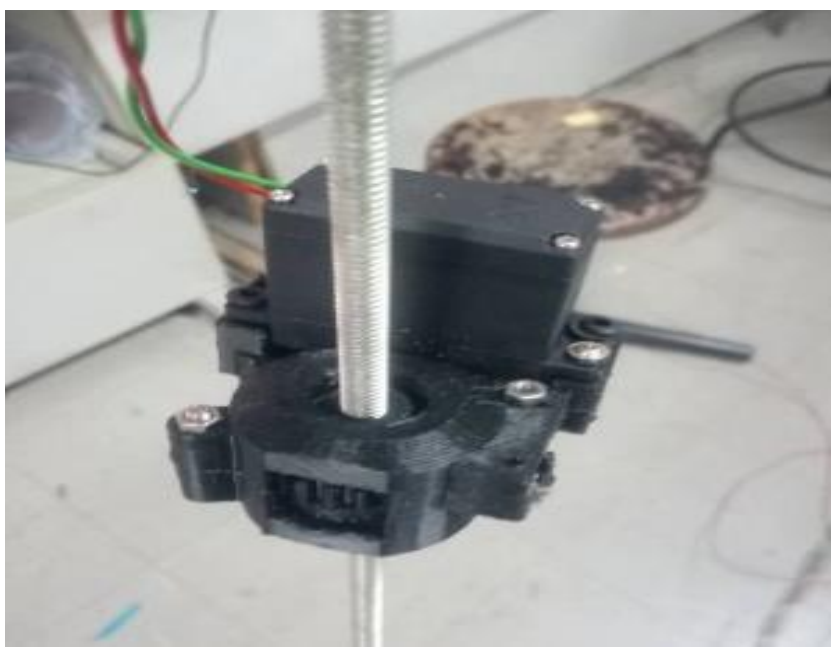

(c)

Fig 5. Sensor and display electronic circuit of new equipment

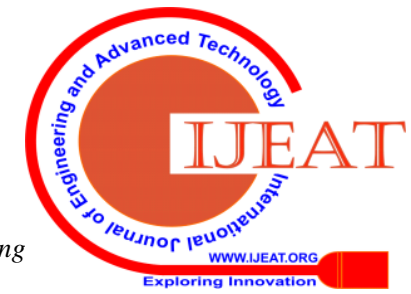


As shown in Fig. 5, for the assembly of the designed circuit described above for all seven stations, as shown in Fig. 5(a), the circuit was assembled to both sensor sets, namely, the water quality set as shown in Fig. 5(b) and the water level set as shown in Fig. 5(c). The system would measure values and transmit data to the system through Message Queuing Telemetry Transport or MQTT Broker by an internet network to a web-based application display (Node Red Dashboard) as shown in Fig. 6(a) and 6(b).

For Fig. 6, the Node Red Dashboard shows the sensor readings for water quality. Testing of operation found that the system could produce accurate sensor measurements and it was possible to determine annual averages for each sensor. As shown in Table 5, it can be seen that each station produced different readings depending on location. In evaluating measured values significant to living, the dissolved oxygen in Khlong Lad Phrao was in the range of $0.64-1.29$, which was very low and not suitable for aquatic life.

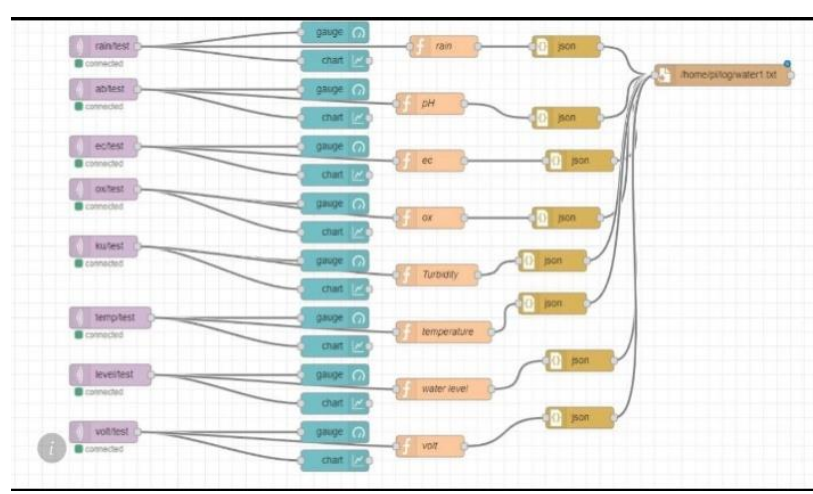

(a)

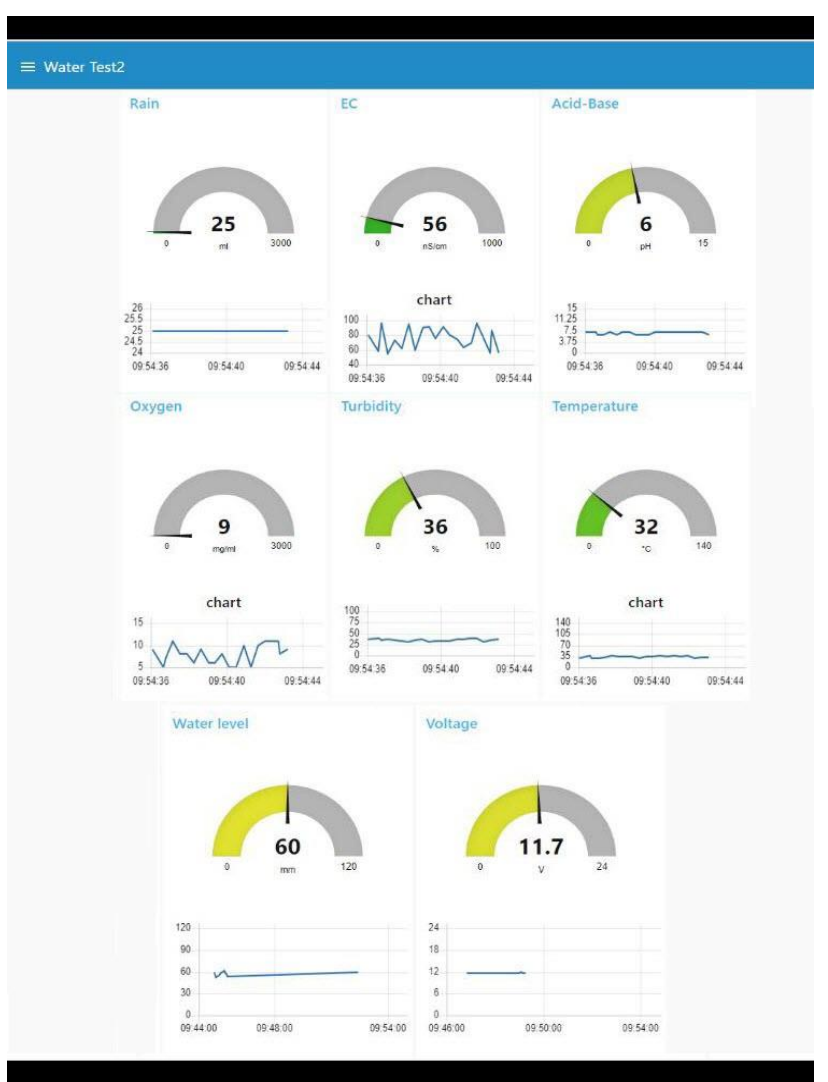

(b)

Fig 6. Node Red Dashboard
Table-V: Average results of 7 Stations at Khlong Lad Phrao

\begin{tabular}{|c|c|c|c|c|c|c|c|}
\hline $\begin{array}{c}\mathrm{N} \\
\mathrm{o}\end{array}$ & $\begin{array}{c}\text { Rain } \\
(\mathrm{mm} \\
)\end{array}$ & $\begin{array}{c}\mathrm{EC} \\
(\mathrm{m} \Omega / \mathrm{cm} \\
)\end{array}$ & $\begin{array}{c}\text { Aci } \\
\mathrm{Bas} \\
\mathrm{e} \\
(\mathrm{PH} \\
)\end{array}$ & $\begin{array}{c}\mathrm{DO} \\
(\mathrm{mg} / \mathrm{L}\end{array}$ & $\begin{array}{c}\text { Turbidit } \\
\mathrm{y} \\
(\mathrm{NTU})\end{array}$ & $\begin{array}{c}\text { Tem } \\
\mathrm{p} \\
\left({ }^{\circ} \mathrm{C}\right)\end{array}$ & $\begin{array}{c}\text { Wate } \\
\mathrm{r} \\
\text { level } \\
(\mathrm{m})\end{array}$ \\
\hline 1 & 0 & 3365 & 6.83 & 0.68 & 314 & 28.98 & 0.69 \\
\hline 2 & 0 & 3341 & 6.74 & 0.64 & 325 & 29.24 & 0.81 \\
\hline 3 & 0 & 3357 & 6.74 & 0.91 & 322 & 29.72 & 0.69 \\
\hline 4 & 0 & 3340 & 6.73 & 0.64 & 326 & 29.24 & 1.11 \\
\hline 5 & 0 & 4402 & 7.69 & 1.29 & 426 & 29.18 & 0.51 \\
\hline 6 & 0 & 3355 & 6.74 & 0.89 & 321 & 29.89 & 0.69 \\
\hline 7 & 0 & 4402 & 7.71 & 1.27 & 427 & 29.24 & 0.48 \\
\hline
\end{tabular}

\section{CONCLUSION}

The research purposes were to design and develop an automatic water level alert system for communities living along Khlong Lad Phrao.

1) The system was capable of monitoring water levels and quality in Khlong Lad Phrao covering such parameters as dissolved oxygen, $\mathrm{pH}$, turbidity and electrical conductivity. Values could be measured accurately in real-time.

2) The system permitted easy access to check various pieces of information through computers or mobile phones via web-based application for all seven stations.

3) The system was capable of measuring water levels in Khlong Lad Phrao and issue alerts through the Line application during emergencies when water levels in Khlong Lad Phrao rise before reaching the set critical level.

4) The system could transmit data to the internet and display obtained data accurately through the Node Red Dashboard application.

For future researches, the authors would like to implement the system in a complex problem considering also time windows constraints for recording data. Next step could be to implement a mobile application for smartphone and tablet in order to records the real usability of this.

\section{ACKNOWLEDGMENT}

Authors would like to thank the Faculty of Industrial Technology, Phranakhon Rajabhat University and the National Research Council of Thailand (NRCT) for financial support.

\section{REFERENCES}

1. A. K. M. Lutfor Rahman, M. Islam, M. Z. Hossain and M. A. Ahsan. Study of the Seasonal Variations in Turag River Water Quality Parameters. African Journal of Pure and Applied Chemistry Vol. 6(10), 2012, pp.144-148.

2. Ali Najah, Ahmed Elshafie, Othman A. Karim and Othman Jaffar. Prediction of Johor River Water Quality Parameters using Artificial Neural Networks. European Journal of Scientific Research Vol.28 No.3 2009, pp.422-435.

3. Bharti N, Katyal.D. Water Quality Indices used for Surface Water Vulnerability Assessment. International Journal of Environmental Sciences. Volume 2, No 1, 2011, pp.154-173.

4. Nabeel M. Gazzaz, Mohd Kamil Yusoff, Ahmad Zaharin Aris, Hafizan Juahir, Mohammad Firuz Ramli. Artificial neural network modeling of the water quality index for Kinta River (Malaysia) using water quality variables as predictors. N.M. 
Gazzaz et al. / Marine Pollution Bulletin 64 2012, pp.2409-2420

5. Pollution Management, Automatic water quality measurement station data reporting system, 2018. http://58.82.183.37/wqm2018/menu/

6. R. Eugene Turner and Nancy N. Rabalais. Changes in Mississippi River Water Quality This Century. Oxford University Press on behalf of the American Institute of Biological Sciences. Journal Vol. 41, No. 3 Mar., 1991, pp. 140-147.

7. M. S. White, M. A. Xenopoulos, K. Hogsden, R. A. Metcalfe and P. J. Dillon. Natural lake level fluctuation and associated concordance with water quality and aquatic communities within small lakes of the Laurentian Great Lakes region. Water-Level Fluctuations Hydrobiologia 2008, Volume 613, pp.21-31.

8. Siva Kumar Subramaniam, Vigneswara Rao Gannapathy, Sivarao Subramonian, Abdul Hamid Hamidon. Flood level indicator and risk warning system for remote location monitoring using Flood Observatory System. WSEAS TRANSACTIONS on SYSTEMS and CONTROL. ISSN: 1991-8763 Issue 3, Volume 5, March 2010. pp.153-163.

9. Enji Sun a,b, Xingkai Zhang and Zhongxue Li. The internet of things (IOT)and cloud computing (CC) based tailings dam monitoring and pre-alarm system in mines. Safety Science Volume 50, Issue 4, April 2012, pp. 811-815.

10. G. Han, L. Liu, S. Chan, R. Yu, and Y. Yang, Pre-Alarm System Based on Real- Time Monitoring and Numerical Simulation Using Internet of Things and Cloud Computing for Tailings Dam in Mines. IEEE Access journal. vol. 5, Oct 2017, pp. 21080-21089.

11. Sheikh Azid, Bibhya Sharma, Krishna Raghuwaiya, Abinendra Chand, Sumeet Prasad, A Jacquier. SMS based Flood Monitoring and Early Warning system. ARPN Journal of Engineering and Applied Sciences Vol. 10, no. 15, Aug 2015, pp.6387-6391.

\section{AUTHORS PROFILE}

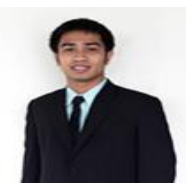

Keeradit Saipattalung, received his Bachelor Degree in electrical engineering from Sripatum University, Thailand and Master Degree in electrical engineering from Kasetsart University, Thailand. Currently, he works as a lecturer at the Department of Electronics and Computer Technology, Faculty of Industrial Technology, Phranakhon Rajabhat University, Thailand. His research interests are automation embedded system, internet of things and renewable energy.

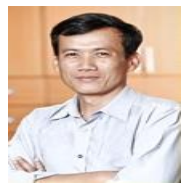

Thongchai Thongyoo, received the Bachelor Degree in communication electrical engineering from Rajamangala Institute of Technology, Thailand and Master Degrees in computer engineering from King Mongkut's University of Technology Thonburi, Thailand. Currently, he works as a lecturer at the Department of Electronics and Computer Technology, Faculty of Industrial Technology, Phranakhon Rajabhat University, Thailand. His main research interests are automation embedded system, internet of things and network computing.



Hattaya Netayaraks, received the Bachelor Degree in education agriculture from Kasetsart University,Thailand and Master Degree in Environmental Science Kasetsart University. She completed the Ph.D in Technology Management from Phranakhon Rajabhat University Thailand. Currently, she works as a lecturer in Faculty of Science and Technology, Phranakhon Rajabhat University. Her research interests consist of basic environmental science, environmental ecology and environmental economics

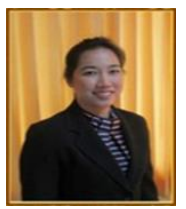

Lakkana Ruekkasaem, received a Bachelor Degree in statistic from Thammasat University, Thailand in 2004. She completed her Master and Ph.D. in industrial engineering from Thammasat University Thailand. Currently, she works as a lecturer in Faculty of Industrial Technology, Phranakhon Rajabhat University. Thailand. She has conducted extensive research in the field of linear programming, analytic hierarchy process and forecasting methods. She also serves as a research committee of the Phranakhon Rajabhat University.

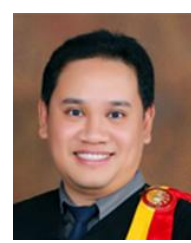

Pasura Aungkulanon, received a Bachelor Degree in industrial engineering from Kasetsart University Thailand. Then, he continued higher education. He completed his Master Degree and $\mathrm{Ph} . \mathrm{D}$. in industrial engineering from Thammasat University Thailand Currently, he works as a lecturer at the Faculty of Engineering, King Mongkut's University of Technology North Bangkok. His expertise is in operational research, artificial intelligence, metaheuristic methods, logistics and supply chain system. 